\title{
A severe complication of pulmonary vein angiography
}

\author{
BRUCE S. ALPERT ${ }^{1}$ AND J. A. GORDON CULHAM
}

From the Division of Cardiology, Department of Paediatrics, and Department of Radiology, The Hospital for Sick Children, Toronto, Ontario, Canada

SUMMARY A pulmonary vein angiogram was performed using a pressure injection with the tip of an end and side hole catheter in a near-wedge position; extravasation of contrast material into a bronchus occurred, causing severe bronchoconstriction. It may be possible to avoid this complication by the use of an end hole balloon catheter in the wedge position, slow flow rates of contrast material, and low pressure injections.

Recent surgical advances for complex malformations involving infundibular or pulmonary valve or artery 'atresias' demand detailed knowledge of mediastinal pulmonary arteries. Recently, Singh (Rigby et al., 1977; Singh et al., 1978) and Nihill et al. (1978) have shown that pulmonary vein angiography can be used to visualise pulmonary artery segments not seen on anterograde cineangiograms. We employed the technique of Singh et $a l$. and experienced a serious complication, the extravasation of contrast material into a bronchus. The patient developed severe respiratory embarrassment requiring intensive care treatment of pulmonary oedema.

\section{Case report}

An 11-year-old girl with severe cyanotic congenital heart disease has been followed at The Hospital for Sick Children, Toronto, since the age of 5 years. A Blalock-Hanlon septectomy was performed elsewhere when she was aged 3 years. When first seen at our institution, in 1972, cardiac catheterisation was interpreted to show double outlet right ventricle, ventricular septal defect, d-malposition of the great arteries, hypoplastic right ventricle, subvalvar and valvar pulmonary stenosis, and absent left pulmonary artery. She underwent a right Blalock-Taussig anastomosis at that time. Cyanosis increased during 1977, and in 1978 a further cardiac catheterisation showed also a straddling right atrioventricular valve and left juxtaposed atrial appendages.

\footnotetext{
${ }^{1}$ Supported by the Ontario Heart Foundation.
}

Further operation was considered but the presence or absence of the left pulmonary artery was in doubt. In order to determine this, we undertook selective bronchial arteriography and left pulmonary vein angiography. The patient was sedated with an intramuscular combination of chlorpromazine, promethazine, and pethidine (Smith et al., 1958). Intravenous doses of diazepam $(10 \mathrm{mg})$ were given after percutaneous entry of the right femoral artery and vein. Selective bronchial artery injections failed to show a left pulmonary artery. A No. 7 Goodale-Lubin catheter was then advanced from the inferior vena cava, across the atrial septum, and into the left lower pulmonary vein. Atropine $(0.04 \mathrm{mg})$ was administered intravenously. After general anaesthesia was induced with halothane and oxygen, the catheter was wedged in the vein and then withdrawn 1 to $1.5 \mathrm{~cm}$. The pressure tracing no longer showed the wedge waveform. Twelve $\mathrm{ml}(0.3 \mathrm{ml} / \mathrm{kg})$ of Hypaque 75 were injected at $20 \mathrm{ml} / \mathrm{s}$. The pressure required for this volume and flow rate was 450 PSI. Much of the dye passed into other pulmonary veins and the left atrium. There was a large extravasation of contrast into the left lower lobe immediately after the injection. The contrast material entered the left lower lobe bronchus and then the left main bronchus (Fig.); the flow of contrast within the bronchus was predominantly toward the hilum. The patient developed increased cyanosis and severe bronchospasm; the anaesthetist noticed increased airway resistance to hand ventilation. Hydrocortisone sodium succinate (100 mg) was given intravenously, as well as another $0.04 \mathrm{mg}$ atropine. The bronchospasm lasted approximately 10 minutes. 


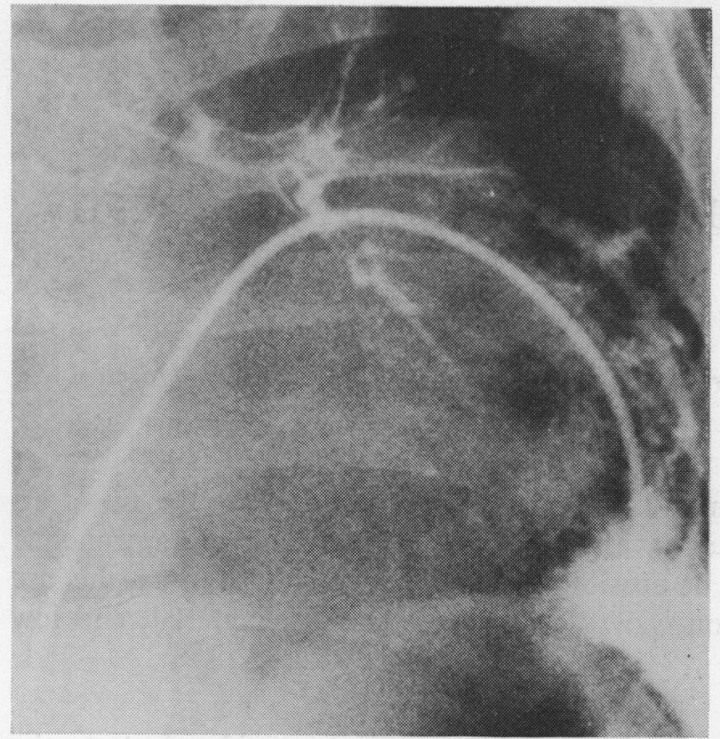

Fig. Cineangiographic frame showing contrast material within the left main bronchus and the parenchymal stain.

No mediastinal left pulmonary artery was seen. There was, however, a large residual stain in the left lower lobe. The patient was taken to the surgical recovery room immediately after stabilisation and subsequent chest $x$-ray films showed resolution of both the stain and local pulmonary oedema over the next 48 hours.

At operation on the third post-catheter day a central aortico-pulmonary anastomosis was performed. No left pulmonary artery was found at that time. The patient was discharged on the 12th postoperative day with improvement of her cyanosis.

\section{Discussion}

The technique used in this patient was that reported by Singh et al. (1978). They describe a pressure injection into an end hole or end and side hole catheter of $1 \mathrm{ml} / \mathrm{kg}$ of contrast material, with the catheter tip just short of the wedge position. They did not state the flow rate achieved. We used an end and side hole catheter (Goodale-Lubin) with a dose of contrast material of only $0.3 \mathrm{ml} / \mathrm{kg}$. The pressure reached at the time of injection was $31.6 \mathrm{~kg} / \mathrm{cm}^{2}$ (450 PSI). In order to show that the catheter tip was not in the wedge position, we repeated the injection at a later time in our laboratory with the catheter tip in a bowl of saline. The pressure again was $31.6 \mathrm{~kg} /$ $\mathrm{cm}^{2}$ (450 PSI). If the catheter had been in the wedge position during the catheterisation, it is likely that the pressure required would have been higher. We do not know what pressure is required to rupture pulmonary vessels and lead to an extravasation of contrast material into the airways.

The only complication mentioned by Singh et al. (1978) was the extravasation of contrast into the pulmonary parenchyma (stain) followed by transient pulmonary oedema. Nadas and Fyler (1972) did not discuss any complications whatsoever. Singh et al. (1978) reported a personal communication from W. Porstmann that extravasation of contrast was essential for proper visualisation of the pulmonary artery.

Differences in the technique of the injection have been reported. Takamiya et al. (1973) recommended a dose of $0.8 \mathrm{ml}$ per $\mathrm{kg}$ of contrast material. Levin et al. (1978) described the injection of 12 to $15 \mathrm{ml}$ of contrast material at a rate of 3 to $4 \mathrm{ml} / \mathrm{s}$, with the catheter in the wedge position. No complications were discussed. Nihill et al. (1978) have the largest reported experience with pulmonary vein angiography. They used Goodale-Lubin or Ross catheters (end and side hole) in the wedge position. They recommended a dose of contrast material of 0.3 to $0.45 \mathrm{ml}$ per $\mathrm{kg}$, injected slowly $(1 \mathrm{ml} / \mathrm{s})$ by hand until visualisation of the pulmonary artery occurred. Then 1 to $2 \mathrm{ml}$ per kg of flush solution were injected at $2 \mathrm{ml} / \mathrm{s}$ to enhance the filling of larger pulmonary artery branches. The complications included cough in all patients and one parenchymal extravasation with a small amount of contrast entering the bronchus. There were no ill-effects from this extravasation. They postulated that the extravasation occurred because of a too rapid rate of injection; our experience supports that hypothesis. They also stated that coughing was associated with extravasation in their patient. They did not describe the sedation used for catheterisation, but our use of general anaesthesia obliterated the cough reflex without preventing this complication.

We followed the recommendations of Singh et al. (1978) for the performance of a pulmonary vein angiogram in a patient with suspected left pulmonary artery atresia. Extravasation of contrast material into the left bronchus caused severe bronchoconstriction and respiratory embarrassment. We speculate that this severe complication was caused by the high pressure and flow dictated by the near wedge position of the catheter. The use of an end hole balloon catheter in the wedge position would permit low flow rates and low pressures and may prevent extravasation of contrast material during pulmonary vein angiography.

\section{References}

Levin, D. C., Fellows, K. E., and Sos, T. A. (1978). Angiographic demonstration of complications resulting from the Waterston procedure. American fournal of Roentgenology, 
131, 431-437.

Nadas, A. S., and Fyler, D. C. (1972). Pediatric Cardiology, 3rd edn. W. B. Saunders, Philadelphia.

Nihill, M. R., Mullins, C. E., and McNamara, D. G (1978). Visualization of the pulmonary arteries in pseudotruncus by pulmonary vein wedge angiography. Circulation, 58, 140-147.

Rigby, M. L., Astley, R., and Singh, S. P. (1977). Demonstration of pulmonary arteries by contrast injection into a pulmonary vein (abstract). British Heart fournal, 39, 352.

Singh, S. P., Rigby, M. L., and Astley, R. (1978). Demonstration of pulmonary arteries by contrast injection into pulmonary vein. British Heart fournal, 40, 55-57.

Smith, C., Rowe, R. D., and Vlad, P. (1958). Sedation of children for cardiac catheterization with an ataractic mixture. Canadian Anaesthetists' Society fournal, 5, 35-40.

Takamiya, M., Tange, I., and Tadokoro, M. (1973). Retrograde pulmonary arteriography: a new approach to opacification of pulmonary artery in pulmonary atresia. In 13th International Congress of Radiology, Madrid (abstract), p. 233 (International Congress Series No. 301). Excerpta Medica, Amsterdam.

Requests for reprints to Dr Bruce S. Alpert, Department of Pediatric Cardiology, The Medical College of Georgia, Augusta, Georgia 30901, USA. 